\title{
Ultrastructural study of human myeloma cells in relation to its function
}

\author{
IKUO SUZUKI, MORINOBU TAKAHASHI, AND SENICHI ITOH \\ From the Laboratory of Ultrastructure Research, Aichi Cancer Center Research Institute, Nagoya, \\ Japan, the Department of Oncology, The Institute of Medical Science, the University of Tokyo, \\ Tokyo, Japan, and Anjo Hospital, Aichi, Japan
}

SYNOPSIS The ultrastructure of neoplastic plasma cells from a patient with prolonged은 multiple myeloma was studied in relation to its function, that is, the secretion of immunoglobulin light chain. Peroxidase-labelled antibodies, each monospecific to its immunoglobulin component chain, were used to localize intracellular immunoglobulin within myeloma cells $\vec{\omega}$ under the electron microscope. By this method, only the $\kappa$ type light chain was detected within myeloma cells in bone marrow tissue of this patient, indicating that the occurrence of free $\kappa$ type light chains in serum and urine was due to the cessation of heavy chain synthesis within the myeloma cells. The $\kappa$ chain was demonstrated as conspicuous electron-dense precipitates in ergastoplasm, its cisternal space, external layer of nuclear membrane, and ribosomes $\frac{\not}{\triangleright}$

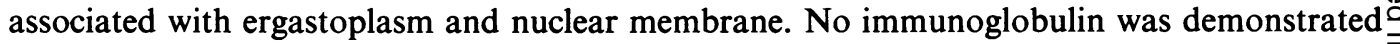
in an atypical Golgi complex, an organelle which is ordinarily engaged in protein synthesis. Numerous crystalline structures and similar inclusion bodies found in myeloma cells appeared to have arisen from the Golgi area, but they did not ever react with the peroxidase label. Discharge of the $\kappa$ chain from the cell seems to be carried out through cell fragmentation, possibly용 caused by progressive distension of the ergastoplasmic cavity.

Extensive morphological studies both at light and electron microscope level of human neoplastic plasma cells (myeloma cells) confirmed their marked pleomorphism (Brecher, Tanaka, Malmgren, and Fahey, 1964; Sorenson, 1964; Maldonado, 1966). It ranged from a cell undistinguishable from the normal plasma cell or its precursors to a cell with a clearly abnormal configuration. Pleomorphism seems to extend to subcellular organelles, since various atypical organelles were reported in some myeloma cells (Maldonado, 1966). Furthermore, a variety of cytoplasmic and nuclear inclusion bodies were reported in some of the myeloma cells (Maldonado, 1966b). Little is known, however, of the functional significance of such abnormal subcellular organelles and various inclusion bodies. This is mainly due to the lack of a method Received for publication 28 August 1969. which allows study of their morphology in을 relation to their function.

In the present work, myeloma cells found in $N$ bone marrow tissue of a myeloma patient were $N$ studied by a combination of immunocytochemistry and electron microscopy using peroxidase-labelled antibodies, each monospecific to the immunoglobulin component chain $\left(\alpha, \gamma, \frac{\bar{\Phi}}{\square}\right.$ $\mu, \kappa, \lambda)$ (WHO Bulletin, 1964). The present result $\stackrel{\oplus}{\sim}$ strongly suggests that release of the free $\kappa$ light $^{0}$ chain into the serum and urine of this patient $\bar{O}$ was caused by synthesis of the complementary heavy chain within myeloma cells ceasing.

It was also demonstrated that the free $\kappa$ type $\frac{\varrho}{\sigma}$ light chain is discharged from the cell mainly through cell fragmentation. The significance of 0 various atypical subcellular organelles and inclusion bodies found in myeloma cells is discussedo를 in relation to immunoglobulin production. 
Materials and Methods

MYELOMA CELLS

Myeloma tissue was obtained by sternal aspiration from a 50-year-old woman. This patient had multiple myeloma developing over three years. We were the first to report numerous crystalline inclusions in kidney tubules and in the cytoplasm of more than $90 \%$ of neoplastic myeloma cells found in the bone marrow. These were never detected in serum or in urine. In the patient's serum, a free light chain of the $\kappa$ type was detected, and a large amount of Bence-Jones protein, also of the $\kappa$ type, was excreted in the urine.

ANTIBODY PREPARATIONS

Antisera were produced in goats against human normal IgG, myeloma IgA, and macroglobulinaemia IgM. Antibodies, each monospecific to the heavy chain class, were specifically purified by using solid immunoadsorbents as described by Takahashi, Yagi, and Pressman (1968). Antibodies, monospecific to the $\kappa$ or $\lambda$ type light chains, were also specifically purified by use of immunoadsorbents from rabbit antisera against the Fab fragment of normal human IgG (Takahashi et al, 1969). Specifically purified antibodies made monospecific by the addition of soluble serum protein with respect to potency and specificity were greatly to be preferred to the antibody globulin. Details of the purification of antibodies and their characterization have already been described (Takahashi et al, 1968, 1969).

CONJUGATION OF ANTIBODY TO

PEROXIDASE

Purified antibody was conjugated to horseradish peroxidase $^{1}$ according to the method described by Nakane and Pierce (1967). For example, $6.1 \mathrm{mg}$ of purified anti- $\kappa$ antibody dissolved in

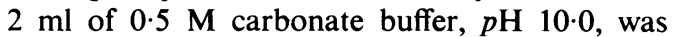
mixed with $7.0 \mathrm{mg}$ of peroxidase, followed by the dropwise addition of $0.25 \mathrm{ml}$ of $0.5 \%$ $\mathrm{p}, \mathrm{p}^{\prime}$-difluoro-m, $\mathrm{m}^{\prime}$-dinitrodiphenyl sulphone ${ }^{2}$ acetone. The reaction was continued at $2^{\circ} \mathrm{C}$ for six hours. After the reaction, peroxidase-conjugated antibody and unreacted antibody were separated from unreacted peroxidase by $50 \%$ ammonium sulphate saturation. Finally, ammonium sulphate was removed by dialysis. The peroxidase-conjugated antibodies thus prepared were tested by immunoelectrophoresis. After electrophoresis was performed, normal human serum or a purified antigen was developed against the corresponding peroxidase-conjugated antibody in the channels. A single and discrete

${ }^{1}$ C. F. Boeringer and Soehne GmbH, Mannheim, Germany. ${ }^{2}$ Tokyo Kasei Kogyo, Tokyo, Japan. precipitin arc was always produced. Staining for ${ }^{\complement}$ peroxidase activity by the enzyme substrate, a亏 mixture of $0.075 \% 3,3^{\prime}$-diaminobenzidine and $0.01 \%$ hydrogen peroxide in $0.05 \mathrm{M}$ tris-Hc芋 buffer, $p \mathrm{H} 7 \cdot 6$, showed a brownish reaction product exactly on the precipitin line.

ELECTRON MICROSCOPY

The whole procedure for staining tissue for ob $-\frac{\bar{D}}{\bar{D}}$ servation with the electron microscope closely followed the method of Nakane and Piercees (1967). Bone marrow tissue was fixed at $4 \mathrm{C} \overrightarrow{\mathrm{O}}$ for $40 \mathrm{~min}$ using $2 \%$ glutaraldehyde as a fixative with gentle agitation. The fixed cell sedimentw was washed overnight at $4{ }^{\circ} \mathrm{C}$ with severa changes of isotonic phosphate buffer, $p \mathrm{H} 7 \cdot 2$ ? containing $4.5 \%$ sucrose. For the reaction, the fixed cell sediment was exposed to peroxidase-t conjugated antibody at a concentration of 0.7 to $1.0 \mathrm{mg}$ per $\mathrm{ml}$ at $4^{\circ} \mathrm{C}$ for eight to 12 hours, followed by extensive washings with the sames buffer, and finally refixed in $2 \%$ glutaraldehyde for one hour to ensure firm binding. The fixative was then washed off with several changes of the phosphate buffer and the cell sediment wase placed in Karnovsky's solution without peroxi. dase (Graham and Karnovsky, 1966; Karnovsky, 1965) at 4 C for one hour, followed by incubation in complete Karnovsky's solution (Graham and Karnovsky, 1966; Karnovsky, 1965) at room temperature for 20 to 30 minutes. The celli sediment was then washed three times with dis $\Rightarrow$ tilled water for $30 \mathrm{~min}$ each time, fixed in $2 \%$ $\mathrm{O}_{\mathrm{s}} \mathrm{O}_{4}$ in phosphate buffer for one hour, thendehydrated and embedded in Epon (Luft, 1961).

The thin sections were cut on an LKB ultratome at a thickness of 500 to $600 \AA$ using a glasso knife. They were examined under a Hitachio $\mathrm{Hu} 11 \mathrm{C}$ electron microscope at $75 \mathrm{kV}$ with or: without uranyl acetate and lead citrate doubleo staining (Sato, 1967). Controls consisted of myeloma cells exposed in the same manner to peroxidase-conjugated normal rabbit globulin $\rightarrow$ cells treated with peroxidase-labelled antibody alone, and cells treated with enzyme substraten alone.

\section{Results}

A variety of cell types were recognized in mye- $-\frac{\Phi}{2}$ loma bone marrow tissue by the electron micro-? scope. Neoplastic plasma cells were, however, ${ }^{-}$ easily distinguished from other cell types of the non-plasma cell series by such morphologica $\stackrel{\mathbb{Q}}{\Omega}$ features as a large, rounded nucleus and a quantity of cytoplasm filled with well developedo ergastoplasm. When fixed cells were treated with peroxidase-conjugated anti- $\kappa$ antibody the pres응 ence of the immunoglobulin $\kappa$ chain was shown as discrete electron-dense precipitates withiro the cytoplasm of more than half of the plasmacytic 
cells (Fig. 1). On the other hand, treating the fixed cell sediment with the peroxidase label of a different antibody specificity failed to reveal any comparable electron-opaque regions in myeloma cells, indicating that the myeloma cell population tested was not producing either immunoglobulin or its heavy chain subunit. Non-plasmacytic cells were never stained by any of the peroxidase-conjugated antibodies except for endogenous peroxidase. Such endogenous peroxidase was prominent within many neutrophil granules encountered in the cytoplasm of granulocytic cells (Fig. 2).

The non-specific adsorption of the peroxidase label can be set aside for several reasons: first, the negative quality of various controls; secondly, the comparison between intact positive cells and intact negative cells; thirdly, the exclusive presence of the $\kappa$ chain in certain limited regions. The $\kappa$ chain was localized separately or simultaneously to ergastoplasm, its membrane, external layer of nucleus, and ribosomes lining the ergastoplasmic and nuclear membranes (Figs. 1-3).

In the myeloma cells tested in the present study, ergastoplasm was very prominent, often occupying a large part of the cytoplasm. The reaction of this organelle with peroxidaseconjugated anti- $\kappa$ antibody indicated that it is actively engaged in the synthesis of the $\kappa$ light chain. Concerning the development of ergastoplasm, we recognized three cell types among the plasma cell population under investigation. The first cell group resembled the differentiating or immature plasma cells found in spleen and lymph node cells (Bernhard and Granboulan, 1964). In it the ergastoplasm was arranged in concentric rows around the nucleus but ergastoplasmic lamellae were hardly distended (Figs. $1,2,6)$. In the second cell type, ergastoplasmic lamellae were fairly distended, often forming anastomoses with neighbouring ergastoplasm. Their general appearance was like a beehive structure (Fig. 7).

The third cell group was distinguished by extremely dilated ergastoplasmic cavities which invaded almost the entire cytoplasm, causing the cytoplasmic matrix to shrink. The cytoplasmic matrix could hardly be recognized except as a narrow, string-like islet narrowed by the distended ergastoplasmic cavities (Figs. 3, 5, 9). In plasmacytic cells of all three groups, ergastoplasm was always the dominant site of $\kappa$ chain accumulation (Figs. 1-3). It was noted that even within the same cell, the intensity of the $\kappa$ chain reaction varied from one ergastoplasm to another. Sometimes positive and negative ergastoplasms were found side by side. In Figs. 1 and 2 are shown electron micrographs of the first cell type which were reacted with peroxidase-conjugated antibody. As shown in Fig. 3, the intracisternal cavity of a myeloma cell of the third cell type was often strongly reactive with the same enzyme label: the electron density of theergastoplasm increased after reaction of the celp with peroxidase-conjugated anti- $\kappa$ antibody Of interest was the occurrence of the $\kappa$ chaing exclusively within ergastoplasm and the nucleato membrane element, including ribosomes asso ciated with them. We never detected the $\kappa$ chains leaking into the compressed cytoplasmic matrixo

The Golgi complex was abundant in all theo myeloma cells under investigation, so forming $\bar{p}$. the discrete Golgi area. As shown in Fig. $8 \mathbb{\complement}$ Golgi lamellae were deficient in the presentw myeloma cells. This is somewhat peculiar, because Golgi lamellae are well developed in various tissues engaged in active protein $\operatorname{syn} \overrightarrow{\vec{\omega}}$ thesis, such as the pancreatic exocrine celf (Caro, 1961; Caro and Palade, 1964). The maing components of the Golgi complex in our mye loma cells were (1) relatively large vacuoles and $\alpha_{\infty}^{\omega}$ (2) smaller, more osmiophilic vesicles containingt electron-dense, homogeneous floccules (Fig. 8) In the Golgi area, we found another kind of vacuole which also contained electron-densesubstance. The electron-dense substance in the latter vacuoles occasionally exhibited fine periodie structures which closely resembled larger para $-\overrightarrow{0}$ crystalline structures encountered in the cyto-o plasm of over $90 \%$ of myeloma cells in the present study (Fig. 8). This substance was en circled by a single, smooth-faced vacuole (Fig. 8)

The paracrystalline structure, when cut $\tan \frac{\mathrm{T}}{\mathrm{N}}$ gentially, exhibited a hexagonal configuration $\frac{\mathrm{D}}{\mathrm{D}}$ with 60 to $90 \AA$ between the two structures A single, smooth-faced membrane, very similaro to that of Golgi vacuoles, surrounded one or two such paracrystalline structures (Fig. 11) The evaluation of the results of staining those. structures was sometimes difficult, because they용 were electron-dense even without peroxidase staining. However, the treatment of myeloma cells with peroxidase-conjugated antibody of any specificity never enhanced their electron density, indicating that they did not containo the substance with the antigenicity of immuno globulin. The membrane of those vacuoles and드. the space surrounded by it were also unreactive with any peroxidase label (Figs. 1-3).

Relatively large, rounded granules (diameter 0 about $1 \mu$ ) were found scattered in the cyto plasm unrelated to other cell organelles. AO lightly electron-dense, homogeneous substance was contained within the granules. Some of them were reactive with peroxidase-conjugated? anti- $\kappa$ antibody (Fig. 2) but not with the peroxi- 0 dase label of any other specificity. They resemble zymogen granules in pancreatic exocrine cells (Caro and Palade, 1964). Our staining result $\Phi_{2}$ suggests that those granules in our myeloma cello are of a similar nature and some of them are engaged in protein secretion.

In general, other cell organelles were scanty and not in a developed form. Smooth-faced ergasto $\frac{60}{3}$ plasm was deficient. Mitochondria, relatively. 


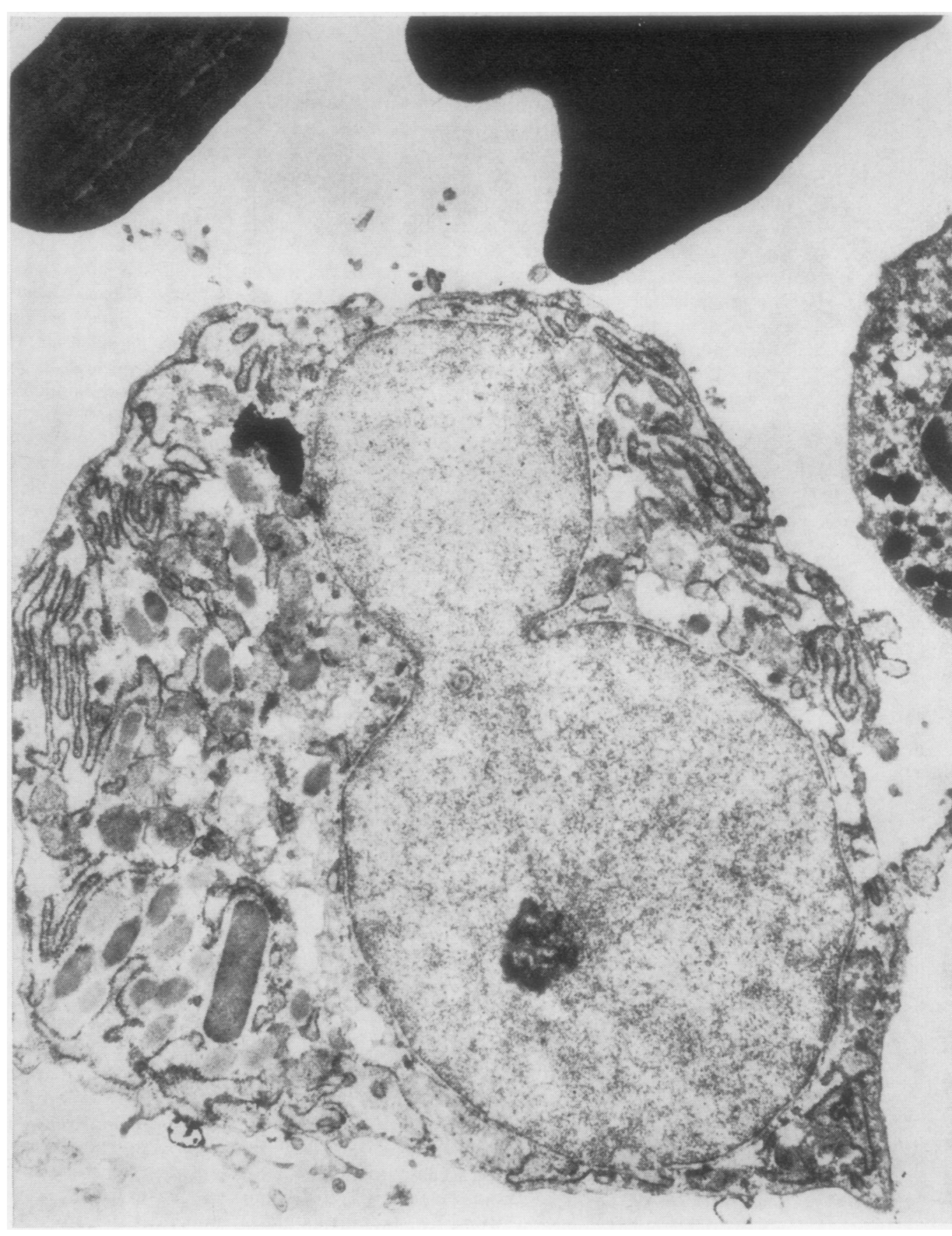

Fig. 1. 
Fig. 2.

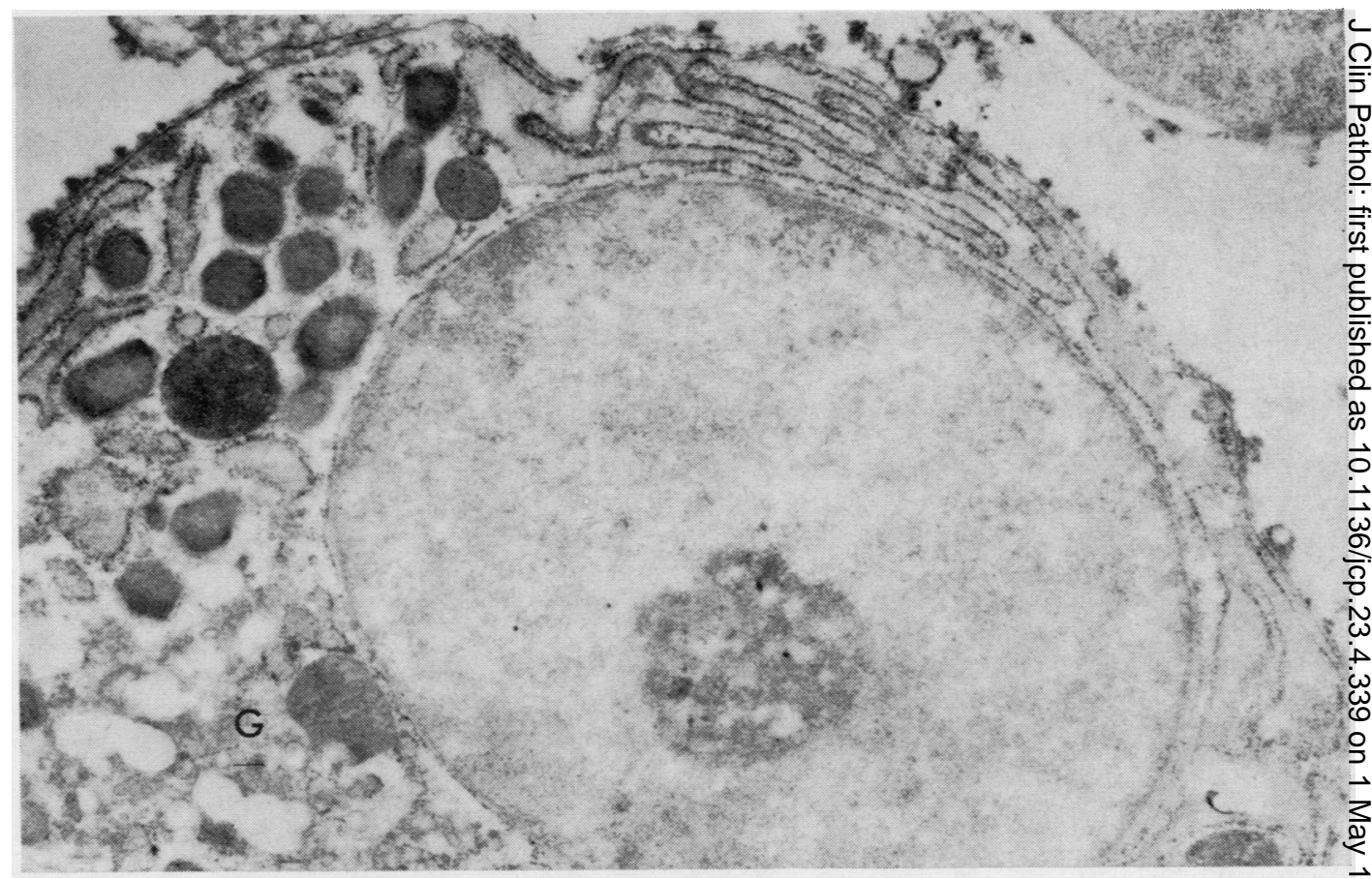

Fig. 3.

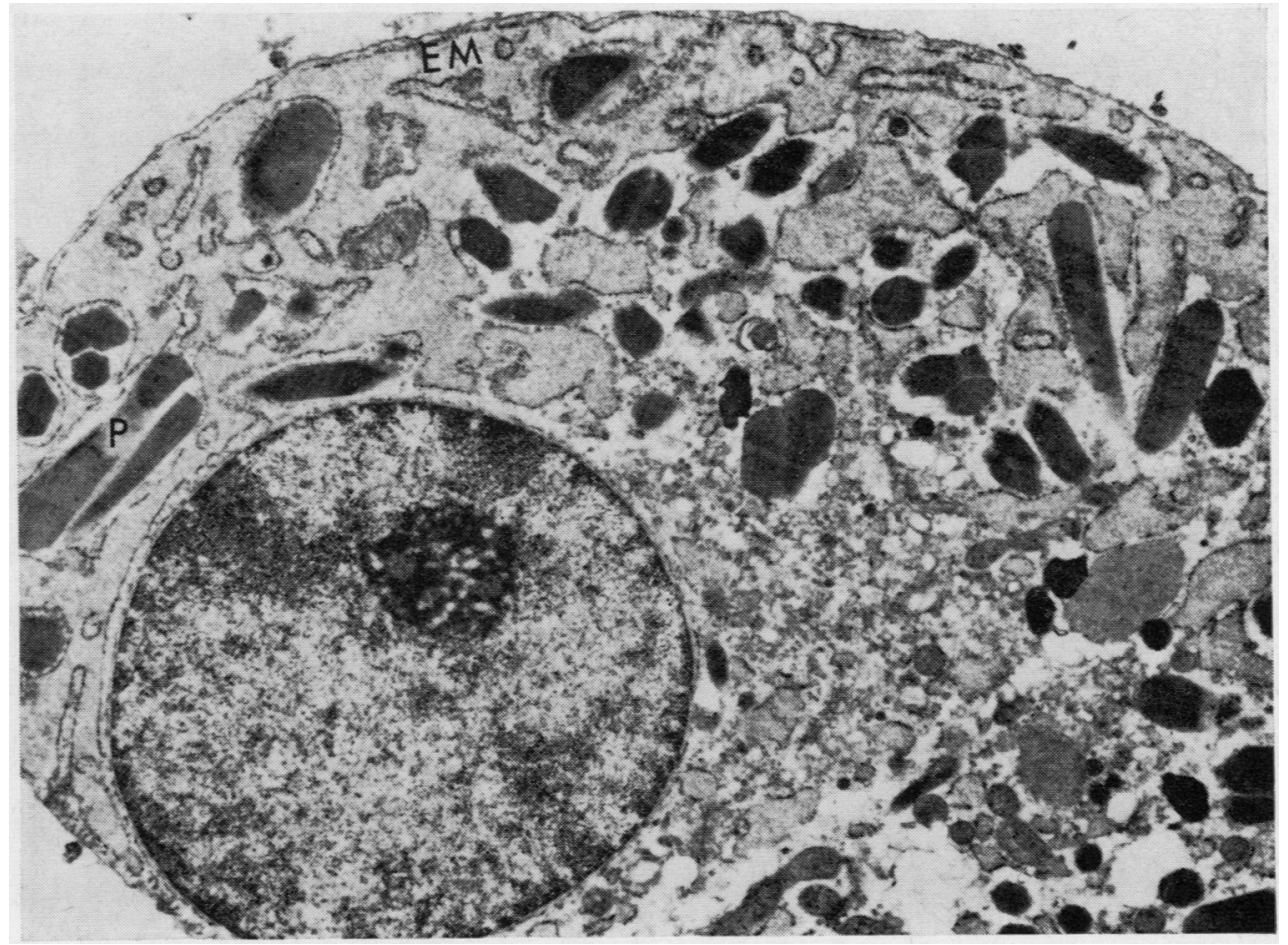

Fig. 3 Electron micrograph of a myeloma cell of

type 3 treated with peroxidase-conjugated anti $\kappa$.

A strongly positive reaction is noted within the ergastoplasmic membrane $(E M)$. A dilated cisternal cavity occupying a large part of the cytoplasm is stained too. Note that paracrystalline structures $(P)$ are always found outside ergastoplasm.

(Lead citrate and uranyl acetate, $\times 10,000$.) 


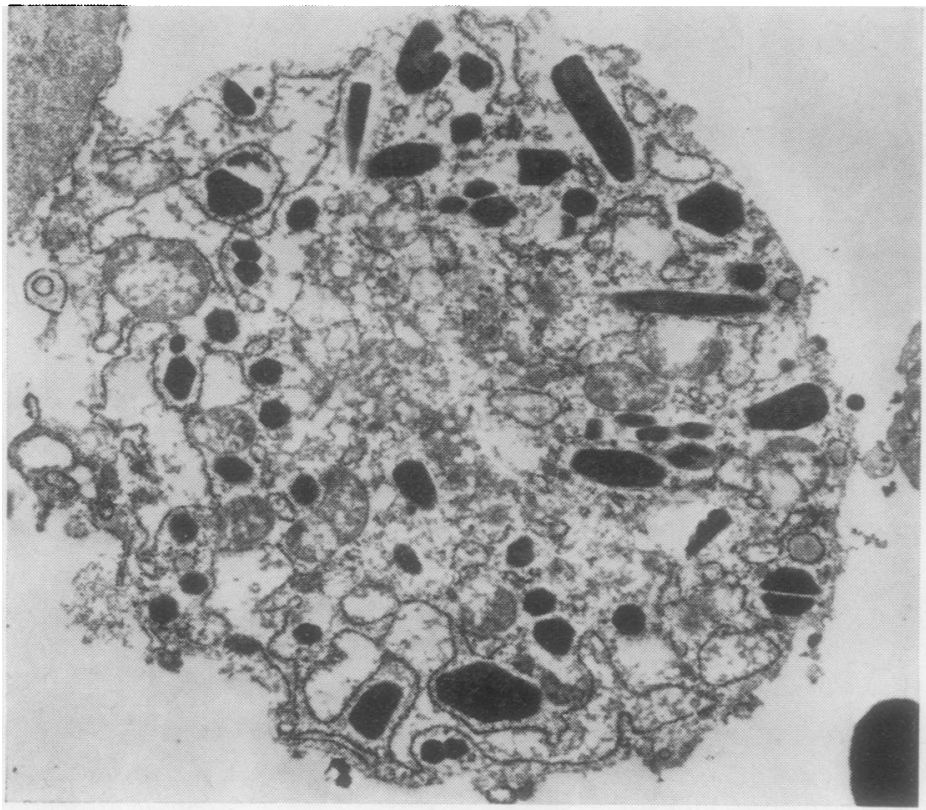

Figs. 4 and 5 Electron micrographs of myeloma cells in which rupture of the membrane and extreme distension of the cisternal cavity are obvious. (Lead citrate and uranyl acetate, $\times$ 7,000 and 11,000.)

Fig. 6 A protein of a myeloma cell of type 1 which was not treated with peroxidase-conjugated antibody. The ergastoplasm is arranged in parallel concentric rows. The cisternal cavity is not dilated. Note the electron lucidity of ergastoplasm without peroxidase reaction. Compare with Figure 1.

(Uranyl acetate and lead citrate, $\times 25,000$.)

Fig. 4.

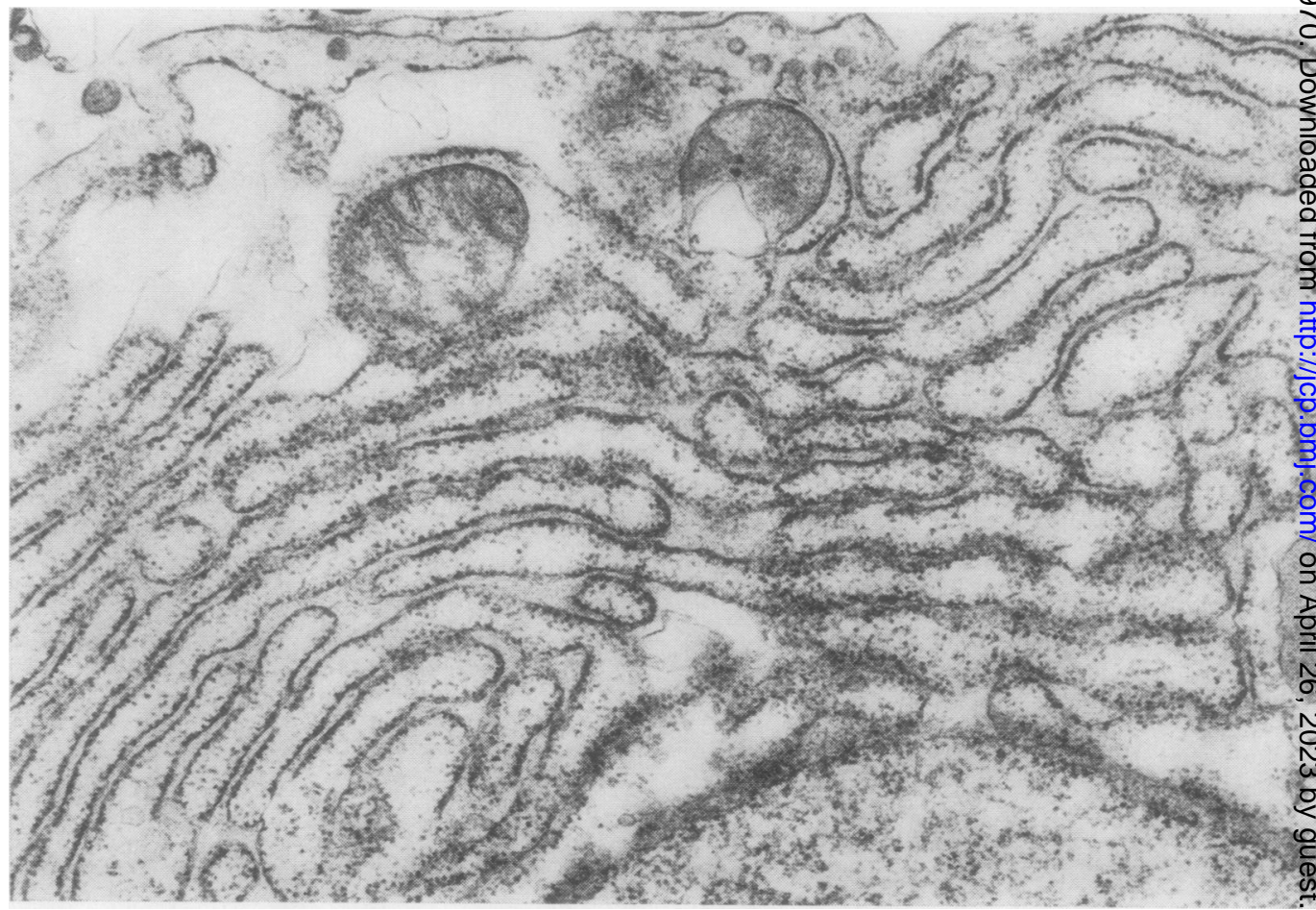




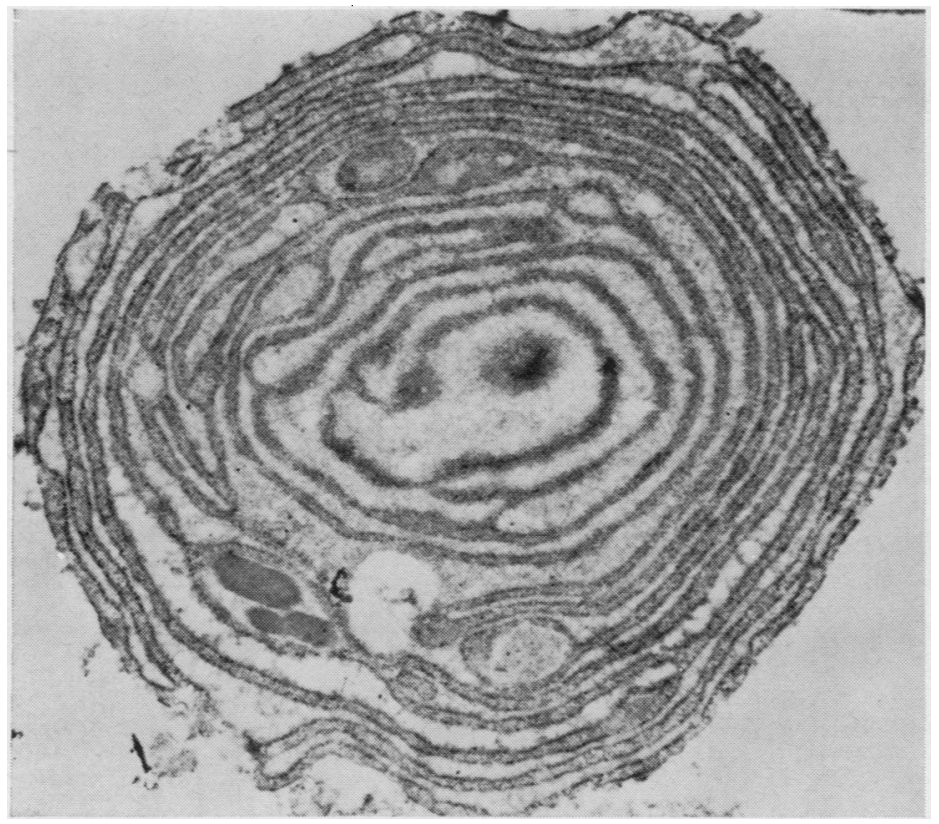

Fig. 5.

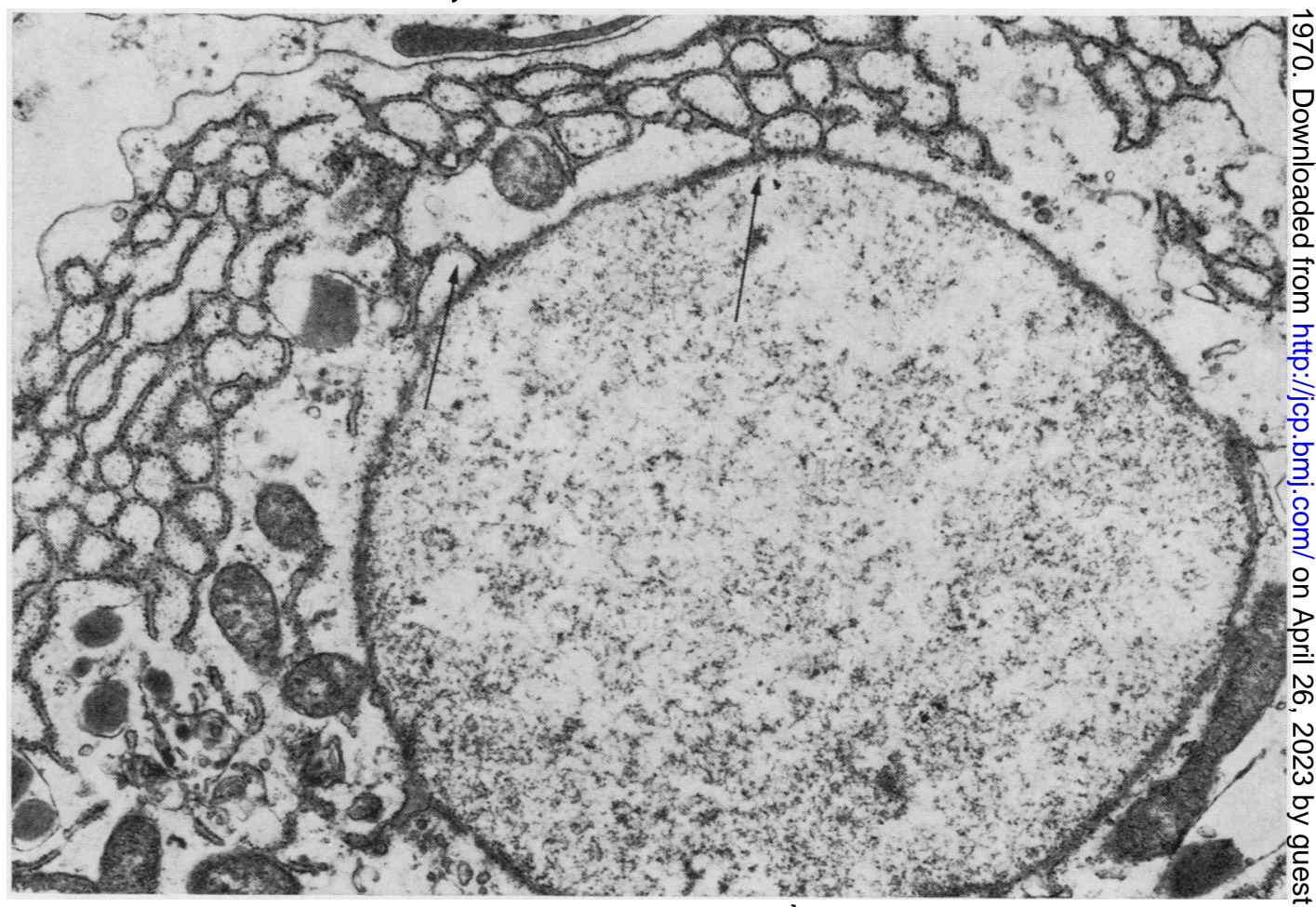

Fig. 7 A myeloma cell of type 2 which was not treated with peroxidase-conjugated antibody. The ergastoplasmic lamellae are arranged in beehive configuration. Note the connecting channel from ergastoplasm to the external layer of nuclear membrane (arrows). Numerous mitochrondria are located in the perinuclear region.

(Lead citrate and uranyl acetate, $\times 13,500$.) 


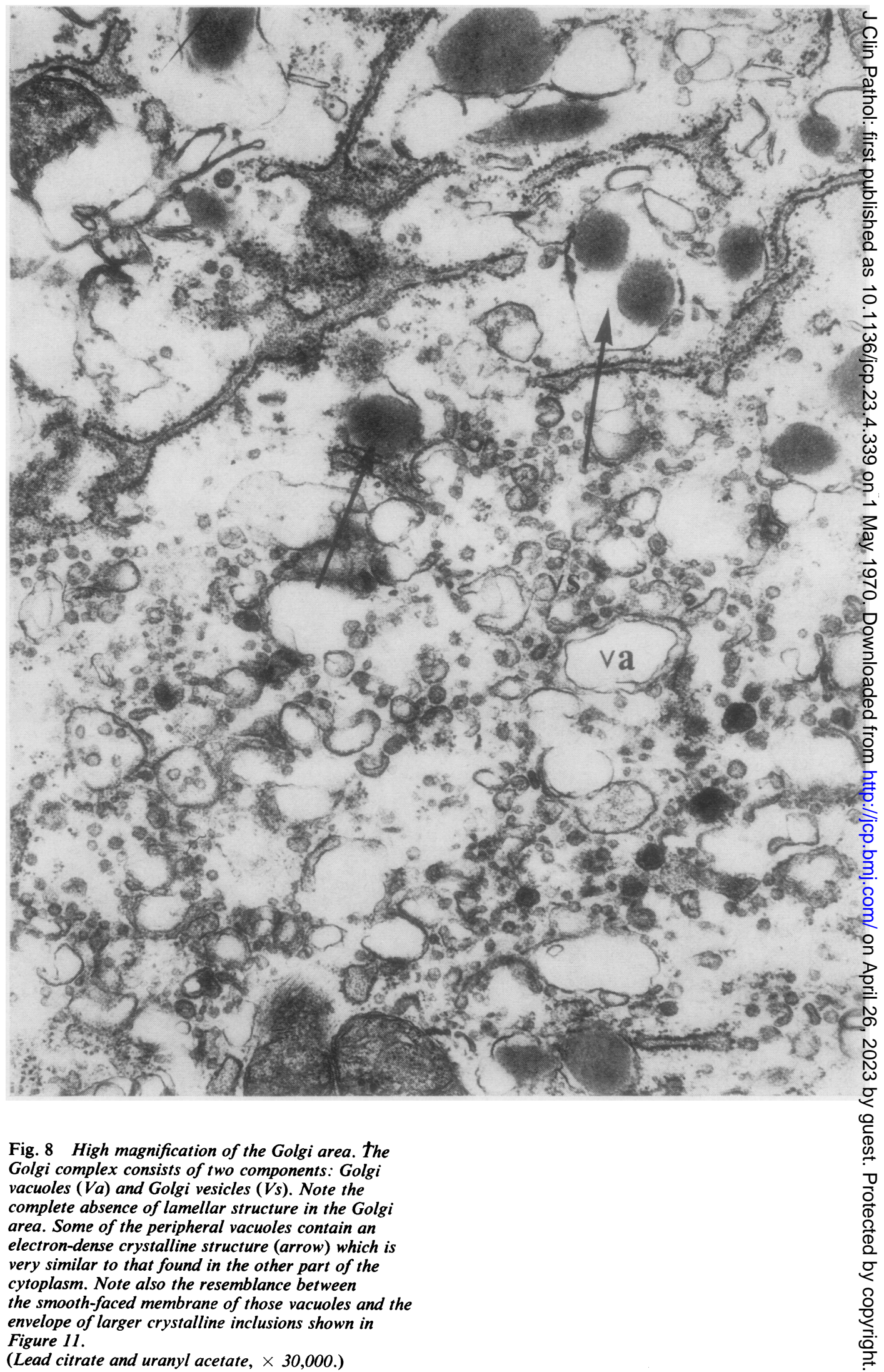


Fig. 9.

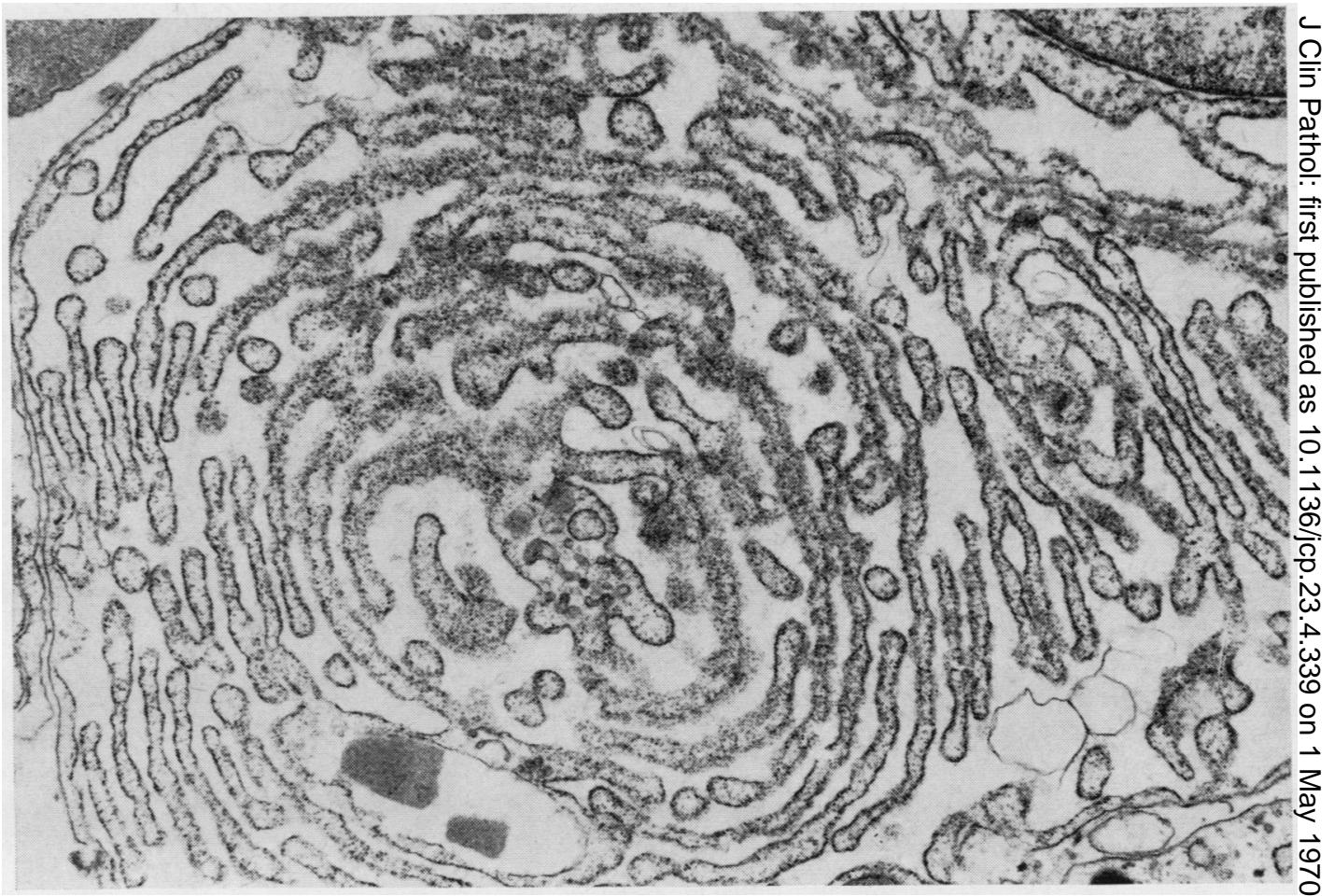

Fig. 10.

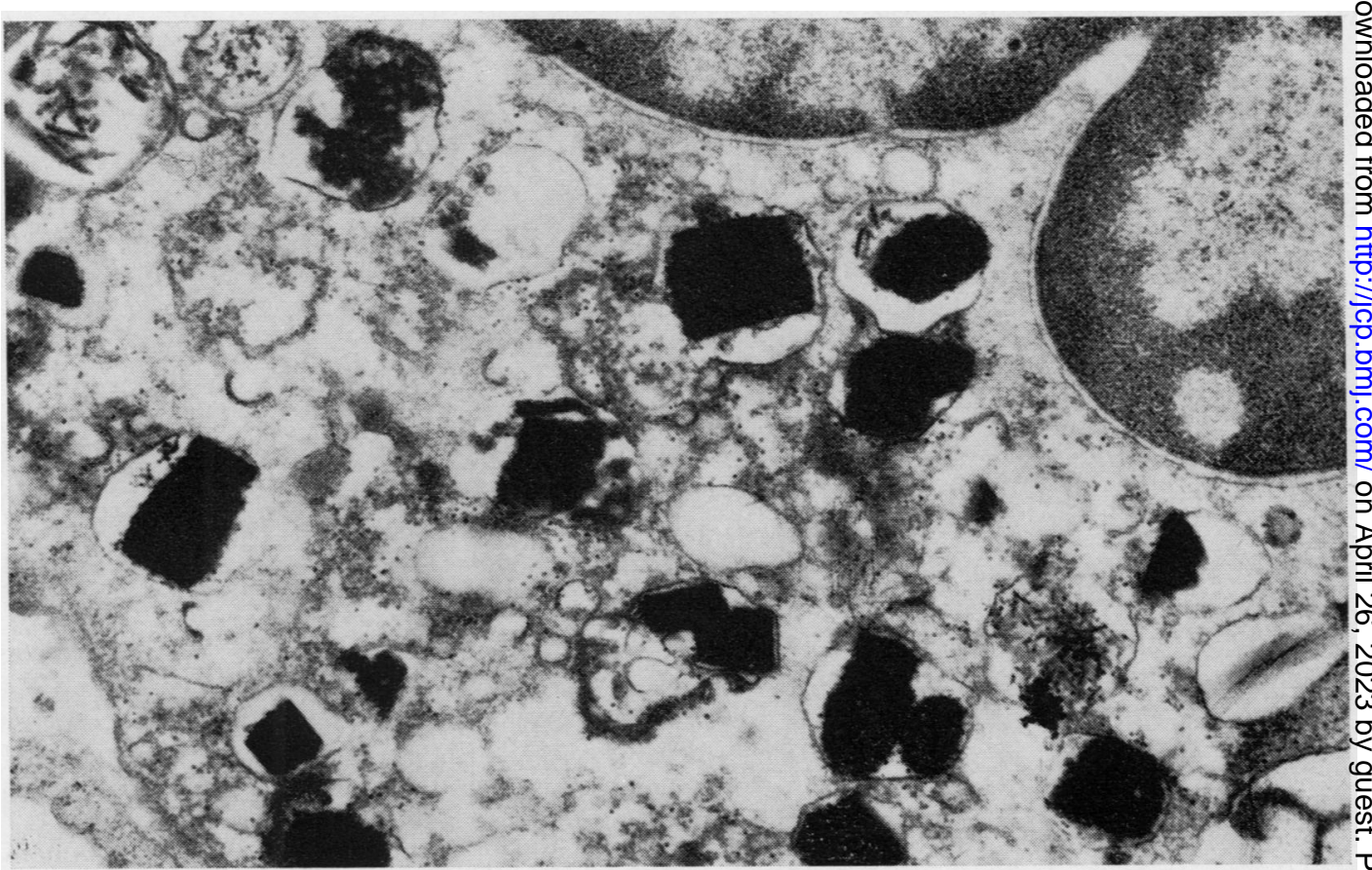

Fig. 9 A myeloma cell of type 3 not treated with peroxidase-conjugated antibody. The extremely dilated cisternal cavity occupies the larger part of the cytoplasm. Paracrystalline structures are found always within the narrowed cytoplasmic matrix outside the ergastoplasmic cavity.

(Lead citrate and uranyl acetate, $\times 13,500$.
Fig. 10 A part of a peculiar myeloma cell containing $\stackrel{\unrhd}{\circledR}$ numerous crystalline structures of irregular configuration. Crystalline structures are highly electrondense and their fragments are found to scatter around them. In such cells, ergastoplasm, mitochondria, and other cell organelles are very scarce. (Lead citrate and uranyl acetate, $\times 25,000$.) 


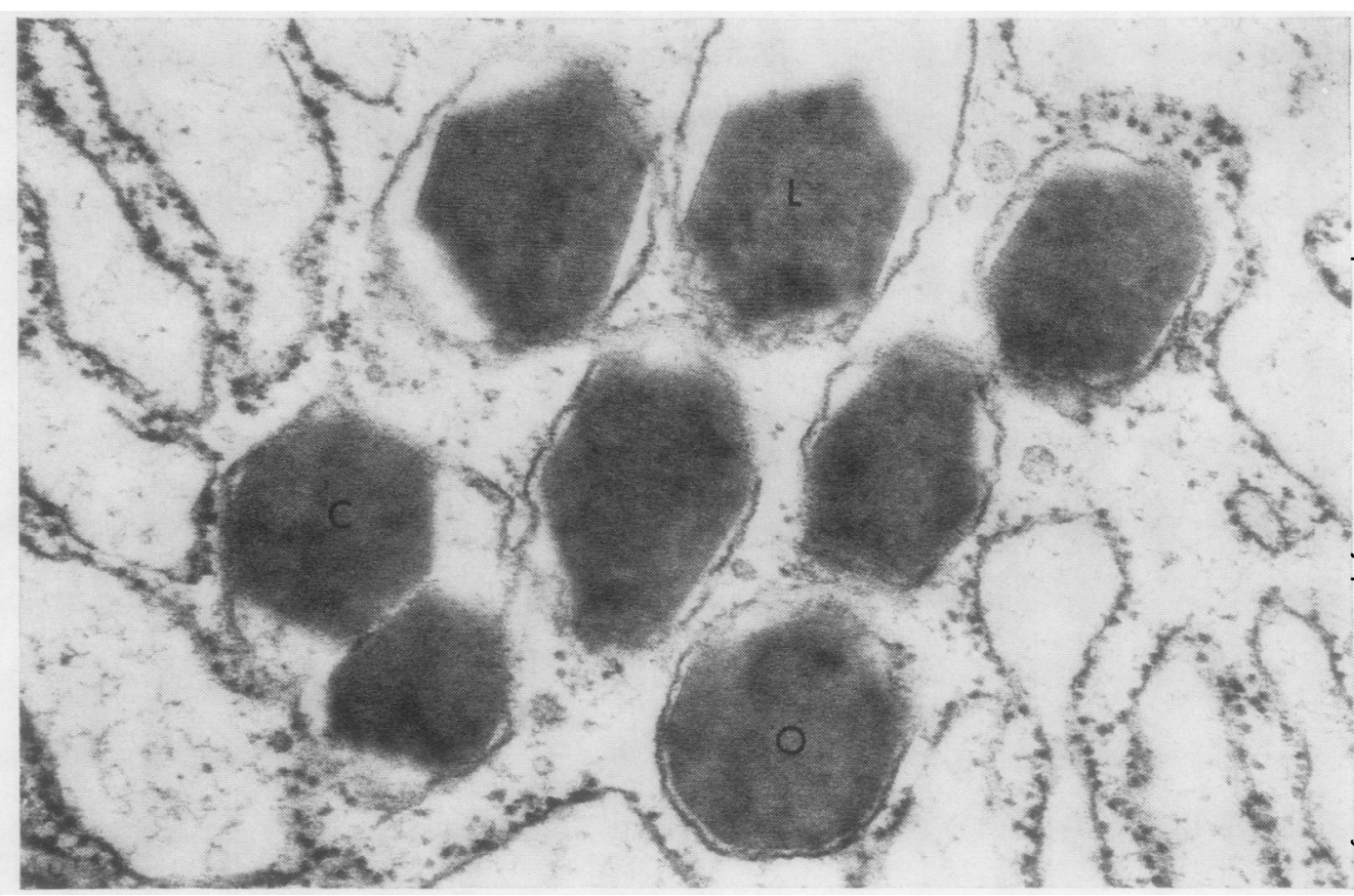

Fig. 11 Electron micrograph of crystalline structures cut in longitudinal $(L)$, cross $(C)$, or oblique $(O)$ section. Note that a single, smooth-faced membrane surrounding one or occasionally two crystalline structures is apparently independent of ergastoplasmic membrane.

(Lead citrate and uranyl acetate, $\times 45,000$.)

small and packed in an electron-dense matrix, were usually found around the nucleus (Fig. 7). All these cytoplasmic organelles were always unreactive with peroxidase-conjugated antibodies of any specificity. Virus-like particles, as described in the primary and transplanted plasma cell of myeloma cells, were never found within our myeloma cells.

\section{Discussion}

Peroxidase-conjugated anti- $\kappa$ antibody showed the intracellular localization of the $\kappa$ chain within the cytoplasm of more than $50 \%$ of myeloma cells under investigation, whereas peroxidaseconjugated antibodies to other immunoglobulin component chains did not. This clearly indicates that the appearance of a free $\kappa$ light chain in the serum and urine of this patient was caused by the synthesis of the complementary heavy chain stopping and not by a block in the complementation of an actually synthesized heavy chain to light chain. Such a blockage has been reported in two ascitic lines of mouse plasma cell tumour secreting only free light chain (Schubert and Cohn, 1968).

The general distribution pattern of the $\kappa$ chain is very similar to that reported with plasmacytic cells of hyperimmunized animals and murine plasma cell tumours (Rifkind, Osserman, Hsu, and Morgan, 1962; de Petris, Karlsbad, and:Pernis, 1963; Leduc, Scott, and Avrameas, 1968, 1969). In our case, positive cells were about $50 \%$ of total plasmacytic cells; positive ergastoplasm coexisted with negative ergastoplasm, sometimes side by side. This may suggest the difference in biosynthetic activity among cellso or even among ergastoplasms within the same
cell.

In positive cells, ergastoplasm was the domi- $N$ nant site of accumulated $\kappa$ chain. The intracisternal cavity of ergastoplasm was also stained $\sigma$ with peroxidase-conjugated anti- $\kappa$ antibody This actually contradicts the hypothesis presented by Schubert and Cohn on the assembly of? mouse myeloma immunoglobulin (Schubert and Cohn, 1968). They postulated that a specifico step is required for the transport of immuno- $\mathrm{D}$ globulin through endoplasmic reticulum into $\frac{?}{D}$ the cisternal cavity. According to their hypothesis, $\frac{\varrho}{\sigma}$ only a complete molecule of immunoglobulin can be secreted into the cisternal cavity, buto subunits of immunoglobulin which are not secreted into the intracisternal cavity are desto troyed in the cytoplasm. 
Three different types of ergastoplasm were recognized in the present myeloma cell population. They differed from one another in the arrangement of ergastoplasmic membrane and development of cisternal cavity. Our type 1 cells seem to correspond to the lamellar type described by Maldonado, Brown, Bayrd, and Pease (1966), but type 2 and type 3 do not fit any of the six types classified by them. The $\kappa$ chain was invariably detected in all of the three types, suggesting that cessation of heavy chain synthesis is independent of morphological change of the ergastoplasm.

The numerous cytoplasmic crystals were always unreactive with any peroxidase label. This was a somewhat unexpected observation, because similar paracrystalline structures found in cytoplasm of prolonged multiple myeloma have been identified as gamma globulin by immunoelectrophoresis (Bessis, 1961). The close morphological analysis of crystalline structures in the present myeloma cells suggests that they originated from the Golgi complex rather from ergastoplasm for the following reasons. (1) We could not detect crystalline structures within a distended ergastoplasmic cavity, but exclusively within a narrowed cytoplasmic matrix (Figs. 3, 4, 9, 11). (2) Crystalline structures were always surrounded by a single, smooth membrane which closely resembles that of Golgi vacuoles (Fig. 11). (3) In the Golgi area numerous large granules were observed containing a lightly electrondense substance in which a periodic fine structure was recognized. The membrane of these granules was undistinguishable from that of Golgi vacuoles (Fig. 8). (4) Peroxidase-conjugated anti-immunoglobulin antibody failed to demonstrate immunoglobulin either in crystalline structures or in the Golgi complex or in inclusion bodies found in the Golgi area. Overall observation suggests that inclusion bodies in the Golgi area are immature forms of larger cytoplasmic crystalline structures with clearer periodicity. The unreactiveness of paracrystalline structures does not necessarily exclude the possibility that they are derived from immunoglobulin or its component subunits (H chain, L chain, or H-L intermediate) (Potter and Kuff, 1964) which were actually synthesized but subsequently destroyed in the cytoplasm. Destruction of such an uncomplemented $\mathbf{H}$ chain (Schubert, 1968) or L chain (Schubert and Cohn, 1968) was reported in certain lines of mouse plasma cell tumours.

Using the ferritin antibody method, Rifkind et al (1962) identified some globulin not only at the point of transition between the ergastoplasm and the Golgi complex but also within the latter structure itself in mouse plasma cell tumours which were secreting gamma globulin. Using peroxidase as an antigen and a marker, Leduc et al (1968) showed that the cisternae of the lamellar portion of the Golgi complex were always filled with peroxidase-positive material ${ }^{c}$ in all antibody-containing plasma cells, whereas the vacuolar components of this apparatus were 0 usually negative. In the present myeloma cells, all elements of the Golgi complex were definitely $\underline{\underline{0}}$ unreactive with peroxidase-labelled anti-immuno- $\overrightarrow{\vec{F}}$ globulin, thus suggesting that those organelles which are ordinarily engaged in the secretion? of immunoglobulin are not active within these음 myeloma cells.

Regarding the manner in which the immuno- $-\widehat{D}$ globulin molecules are released in plasma cells, normal and abnormal, two hypotheseshave been proposed. The first concept assumes ${ }_{-}$ that the Golgi membrane system is involved in $\vec{\omega}$ packaging protein into vesicles. Those vesicles? then transport the protein to the cell surfaces where it is discharged. The distribution of Golgi ${ }_{\omega}$ vesicles containing electron-dense material both ${ }_{-}$ in normal (Bernhard and Gronboulan, 1964) and neoplastic (Dalton, Potter, and Merwin, $\bullet$ 1961) plasma cells suggests that such a mech-응 anism may be active in these cells (Bessis, 1961). $-\overrightarrow{ }$ Reports by Rifkind et al (1962) and Leduc et al (1968) provide further support for this hypothesis.

Another possible mechanism for the secretion of immunoglobulin by plasma cells was firsto proposed by Ortega and Mellors (1957) in their immunofluorescence study. This involves the rupture of the cell itself thereby extruding itso contents. Thiéry (1960) and Bessis (1961) also $\Phi$ described a similar process of cytoplasmic fragmentation, termed 'clasmatosis', in plasma윽 cells of immunized animals and in myeloma cells. The extreme distension of ergastoplasmic cavities in plasma cells containing Russell bodies or protein crystals (Thiéry, 1960) likewise suggestso that disintegration of the cell itself may be onemode of release of proteins in plasma cells.

The present result seems to be more con-ô sistent with the second hypothesis, since the Golgi complex is not active in the secretion? of immunoglobulin, and rupture of cytoplasmic $>$ membrane is frequently found in cells with extremely distended ergastoplasmic cavities. N However, the presence of small numbers of zymogen-like granules which are reactive with 0 peroxidase-conjugated anti $\kappa$ suggests that the $\omega$ first mechanism is partly still at work too.

It is fruitless and may be misleading to drawo any general conclusion regarding the secretory mechanism of pathological immunoglobulin in ? myeloma cells from the study of only a single ${ }^{\circ}$ case of myeloma. It is postulated, however, that a similar immunocytochemical analysis of a@ greater number of tumours and, in particular, $\stackrel{D}{\varrho}$ a comparison between two types of myeloma cells, one producing a complete molecule of immunoglobulin and the other only its lighto chain portion, would provide a key to an understanding of the actual nature of atypical sub- $\bar{?}$ cellular organelles and their relation to defective 
immunoglobulin synthesis observed in the second kind of myeloma cell.

\section{References}

Bernhard, W., and Granboulan, N. (1960). Ultrastructure of immunologically competent cells. In Ciba Foundation Symposium on Cellular Aspects of Immunology, edited by G. E. W. Wolstenholme and M. O'Connor, pp. 92-121, Churchill, London.

Bessis, M. C. (1961). Ultrastructure of lymphoid and plasma cells in relation to globulin and antibody formation. Lab. Invest., 10, 1040-1067.

Brecher, G., Tanaka, Y., Malmgren, R. A., and Fahey, J. L. (1964). Morphology and protein synthesis in multiple myeloma and macroglobulinaemia. Ann. N.Y. Acad. Sci., 113, 642-653.

Caro, L. G. (1961). Electron microscopic radioautography of thin sections: the Golgi zone as a site of protein concentrations in pancreatic acinar cells. J. biophys. biochem. Cytol., 10, 37-45.

Caro, L. G., and Palade, G. E. (1964). Protein synthesis, storage, and discharge in the pancreatic exocrine cell: an autoradiographic study. J. Cell Biol., 20, 473-495.

Dalton, A. L., Potter, M., and Merwin, R. M. (1961). Some ultrastructural characteristics of a series of primary and transplanted plasma-cell tumors of the mouse. $J$. nat. Cancer Inst., 26, 1221-1235.

de Petris, S., Karlsbad, G., and Pernis, B. (1963). Localization of antibodies in plasma cells by electron microscopy. J. exp. Med., 117, 849-862.

Graham, R. C., Jr., and Karnovsky, M. J. (1966). The early stages of absorption of injected horseradish peroxidase in the proximal tubules of mouse kidney: ultrastructural cytochemistry by a new technique. J. Histochem. Cytochem., 14, 291-302.

Karnovsky, M. J. (1965). Vesicular transport of exogenous peroxidase across capillary endothelium into the $\mathrm{T}$ system of muscle. J. Cell Biol., 27, 49-50A.

Leduc, E. H., Scott, G. B., and Avrameas, S. (1969). Ultrastructural localization of intracellular immune globulins in plasma cells and lymphoblasts by enzyme-labeled antibodies. J. Histochem. Cytochem., 17, 211-224.

Luft, J. H. (1961). Improvements in epoxy resin embedding methods. J. biophys. biochem. Cytol., 9, 409-414.

Maldonado, J. E., Brown, A. L., Jr., Bayrd, E. D., and Pease, G. L. (1966). Cytoplasmic and intranuclear electron-dense bodies in the myeloma cell. Arch. Path., 81, 484-500.
Maldonado, J. E., Brown, A. L., Jr., Bayrd, E. D., and Pease, G. L. (1966). Ultrastructure of the myeloma cell. Cancer (Philad.), 19, 1613-1627.

Nakane, P. K., and Pierce, G. B., Jr. (1967). Enzyme-labeled $U$ antibodies for the light and electron microscopic localization of tissue antigens. J. Cell Biol., 33, 307-318.

Ortega, L. G., and Mellors, R. C. (1957). Cellular sites of formation of gamma globulin. J.exp. Med., 106, 627-640.

Potter, M., and Kuff, E. L. (1964). Disorders in the differentiation $\overline{\bar{\omega}}$ of protein secretion in neoplastic plasma cells. J. molec Biol., 9, 537-544.

Rifkind, R. A., Osserman, E. F., Hsu, K. C., and Morgan, C. ̄ (1962). The intracellular distribution of gamma globulin in a mouse plasma cell tumour (X5563) as revealed by $\vec{\nabla}$ fluorescence and electron microscopy. J. exp. Med., 116, 423-432.

Sato, T. (1967). J. Electron Microsc., Chiba Cy, 17, 193.

Schubert, D. (1968). Immunoglobulin assembly in a mousemyeloma. Proc.nat. Acad.Sci. (Wash.), 60, 683-690.

Schubert, D., and Cohn, M. (1968). Immunoglobulin biosynthesis III. Blocks in defective synthesis. J. molec. Biol., 38, $\vec{\omega}$ 273-288.

Sorenson, G. D. (1964). Electron microscopic observations of bone marrow from patients with multiple myeloma.O Lab. Invest., 13, 196-213.

Takahashi, M., Yagi, Y., and Pressman, D. (1968). Preparation. of fluorescent antibody reagents monospecific to heavy? chains of human immunoglobulin. J. Immunol., $100, \omega$ 1169-1175.

Takahashi, M., Yagi, Y., and Pressman, D. (1969). Preparation of fluorescent antibody reagents monospecific to light chains of human immunoglobulin. J. Immunol., 102, 1268-1273.

Thiéry, J. P. (1960). Microcinematographic contributions to the study of plasma cells. In Ciba Foundation Symposium or Cellular Aspects of Immunity, edited by G. E. W. Wolsten $-\vec{C}$ holme and M. O'Connor, pp. 59-91. Churchill, London.

World Health Organization. (1964). Nomenclature for humano immunoglobulins. Bull. Wld Hlth Org., 30, 447-450. 